\title{
Is the Comorbidity Between Social Phobia and Panic Disorder Due to Familial Cotransmission or Other Factors?
}

\author{
Ewald Horwath, MD, MSc; Susan I. Wolk, MD; Risë B. Goldstein, PhD, MPH; Priya Wickramaratne, PhD; \\ Christina Sobin, PhD; Phillip Adams, PhD; Jennifer D. Lish, PhD; Myrna M. Weissman, PhD
}

\begin{abstract}
Background: We previously reported significantly elevated rates of social phobia in relatives of probands with panic disorder compared with relatives of other proband groups. This study further investigates the relationship between social phobia and panic disorder.

Method: This sample is from a family study that included 193 probands from four mutually exclusive groups (patients with panic disorder, patients with panic disorder and major depression, patients with early-onset major depression, and normal controls) and 1047 of their adult first-degree relatives. Best-estimate diagnoses were completed using DSM-III-R criteria.
\end{abstract}

Results: Social phobia and agoraphobia aggregate in the families of probands with panic disorder without major depression. Social phobia frequently co-occurs with panic disorder in relatives, but the risk for comorbidity does not vary across proband groups.

Conclusions: The familial aggregation of social phobia with panic disorder may be explained by the aggregation of panic disorder in relatives of probands with panic disorder combined with the tendency for panic disorder to occur comorbidly with social phobia in individuals.

(Arch Gen Psychiatry. 1995;52:574-582)
From the Department of Psychiatry, the College of Physicians and Surgeons of Columbia University (Drs Horwath, Wolk, Wickramaratne, Sobin, Adams, and Weissman), and the Division of Clinical and Genetic Epidemiology, New York State Psychiatric Institute (Drs Goldstein, Wickramaratne, Sobin, Adams, and Weissman), New York, NY; and the Department of Psychiatry, the Medical College of Pennsylvania, Philadelphia (Dr Lish).
EVERAL STUDIES have demonstrated substantial comorbidity between social phobia and panic disorder. Schneier and colleagues, ${ }^{1}$ in an analysis of the Epidemiologic Catchment Area (ECA) data, found that subjects with social phobia had a greater than threefold increased risk for lifetime panic disorder when compared with those without social phobia. In a clinical sample of 57 patients with social phobia, Van Ameringen and associates $^{2}$ found that $49 \%$ had a lifetime diagnosis of panic disorder. Other investigators $^{3-7}$ have reported rates of social phobia ranging from $6 \%$ to $53 \%$ in subjects with panic disorder.

Clinical, epidemiologic, and biologic data support a diagnostic boundary between social phobia and panic disorder, suggesting that these two disorders are distinct even though they frequently cooccur. $^{8-11}$ There is evidence that social phobia and panic disorder have different ages at onset, prevalence rates, gender ratios, sensitivities to sodium lactate infusion and carbon dioxide inhalation, patterns of helpseeking behavior, and pharmacologicresponse profiles. ${ }^{8.12}$

The consensus seems to be that social phobia and panic disorder are two dis- tinct syndromes with substantial comorbidity. It is not clear, however, whether social phobia and panic disorder cooccur because they share common risk factors, whether one disorder causes the other, or whether social phobia comorbid with panic disorder is a distinct syndrome that is different from either disorder alone.

Family studies can help differentiate the cause for co-occurrence from among these alternative explanations of comorbidity by providing data on familial cotransmission of the two disorders. To date, family studies have not established a familial relationship between social phobia and panic disorder.

There is considerable evidence that panic disorder is highly familial. ${ }^{13-19} \mathrm{How}-$ ever, the familiality of social phobia has been less well studied. Fyer and colleagues,${ }^{20}$ in the only published direct interview family study of social phobia, found that relatives of probands with social phobia had a threefold increased risk

\section{See Methods on next page}




\section{METHODS}

\section{PROBAND SELECTION}

The study methods have been described in detail elsewhere. ${ }^{13,14}$ Probands were selected from research clinics at Yale University, New Haven, Conn, and the New Haven site of the ECA study. Probands selected were white, were between 18 and 70 years of age, and met the criteria for one of the four groups.

Persons who initially met the demographic and diagnostic inclusion criteria were reinterviewed blindly using the Schedule for Affective Disorders and SchizophreniaLifetime Version for Anxiety Disorders (SADS-LA). ${ }^{26}$ The SADS-LA generated RDC and was modified to incorporate DSM-III and DSM-III-R criteria as well.

\section{DIAGNOSTIC CRITERIA FOR PROBANDS}

Probands were excluded from all groups if they met criteria for schizophrenia, mania, Briquet's syndrome, antisocial personality disorder, or anorexia. Substance abuse was not considered exclusionary if it was secondary to the primary diagnosis, primary but mild, or followed by a significant period of recovery prior to the onset of the inclusion diagnosis. The diagnostic criteria for each specific group were as follows.

\section{Early-Onset MDD}

A history of MDD by modified RDC with the first episode having occurred at or before the age of 30 years was required. ${ }^{27}$ The modification to the RDC included duration of illness of at least 4 weeks and impairment of social functioning in the major social role. Probands were excluded from this group if they had panic attacks or panic disorder during their lifetime by any diagnostic criteria at any level of certainty.

\section{Panic Disorder With or Without MDD}

Probands were required to meet DSM-III criteria for panic disorder. For the comorbid group, probands were additionally required to meet RDC for MDD, modified as described above. Probands in the panic disorder without MDD group were excluded if they reported any evidence of MDD during their lifetime by any diagnostic system at any level of certainty.

\section{Never Mentally Ill Controls}

Probands were included if they had received no lifetime psychiatric diagnosis during any of the three waves of the ECA interviews based on the Diagnostic Interview Schedule $^{28}$ and on reinterview with the SADS-LA. Some controls who were classified as never mentally ill may have had phobia symptoms, but these symptoms were insufficient to meet DSM-III criteria for a phobic disorder.

\section{RELATIVES}

After acceptance of the proband into the study, all firstdegree relatives (FDRs), living or deceased, aged 6 years and older were enumerated systematically using the Pedigree Collection Form. ${ }^{29}$ Permission to contact relatives was obtained from the proband, and all consenting relatives were directly interviewed by SADS-LA. This resulted in direct SADS-LA interviews in $52 \%$ of all living FDRs, a percentage that did not vary across proband groups. In addition to the SADS-LA, family history on all probands and FDRs was collected from all probands and interviewed relatives using a modified Family History Method for RDC. ${ }^{30-32}$ The interviewers were clinicians with master's degrees in social work or doctor of philosophy degrees in clinical psychology or were advanced doctoral students in clinical programs. Interviewers were blind to the diagnostic group of the proband.

\section{BEST-ESTIMATE DIAGNOSES}

Best-estimate diagnoses were made by a psychiatrist or a clinical psychologist with a doctor of philosophy degree on each proband or relative based on all available information from the interview, the family history, and medical records. ${ }^{33}$ The best estimator was blind to the diagnostic group and to the status of the individual as proband or relative. Thirty-six of the 229 probands were dropped from the study because they did not meet criteria for any of the four groups when the best-estimate diagnoses were completed. Thus, the final sample consisted of 193 probands and 1047 adult FDRs.

\section{DATA ANALYSIS}

Crude lifetime rates of disorders were compared using $x^{2}$ tests. Age-corrected lifetime rates were derived from KaplanMeier analyses. Adjusted hazard ratios were derived from proportional hazards regression models that controlled for gender, age, and interview status of relatives and proband ascertainment source. This method applies multiple regression to a survival distribution to yield the age-specific incidences of disorders in relatives while controlling for potentially confounding variables. We controlled for proband ascertainment source because of a previous finding that ascertainment source confounded the effect of proband group, although it did not independently influence the rates of social phobia in relatives. ${ }^{34}$ The strength of the association between panic disorder and social phobia in relatives was measured by odds ratios calculated from $2 \times 2$ tables stratified by proband group. The homogeneity of the odds ratio across proband groups was evaluated with the BreslowDay statistic. for social phobia compared with relatives of the never mentally ill subjects. Another study, ${ }^{21}$ which used a less sensitive family history method, found rates of social phobia in the relatives of probands with social phobia that were higher than those in the relatives of probands with panic disorder but not different from the rates in the relatives of normal controls.

The few studies on the cotransmission of phobias and other anxiety disorders have produced findings that are difficult to interpret. Family studies that used 
Research Diagnostic Criteria (RDC), ${ }^{22}$ which do not distinguish one phobic subtype from another, have found aggregation of phobias in the relatives of probands with panic disorder or generalized anxiety disorder (GAD). ${ }^{10,11,15}$ However, these studies did not control for the effect of comorbid phobic disorders or major depression (MDD) among probands. Family studies that have differentiated between phobic subtypes using DSM-III $I^{23}$ or DSM-III- $R^{24}$ criteria have not found elevated rates of social phobia in the relatives of probands with panic disorder or agoraphobia. ${ }^{7,16,21,25}$ Similarly, Fyer et al ${ }^{20}$ did not find aggregation of panic disorder in the relatives of probands with social phobia.

Weissman et $\mathrm{al}^{13}$ recently reported results from a family study indicating that the rates of social phobia were significantly higher in the relatives of probands with panic disorder than in the relatives of normal controls, and this finding was not explained by the presence of comorbid social phobia in the probands with panic disorder. ${ }^{14}$ To the best of our knowledge, this is the first specific report of a familial association between social phobia and panic disorder.

The purpose of this article is to explore the possible explanations for this association. We propose several alternative hypotheses that could explain our finding of familial coaggregation of social phobia and panic disorder:

Hypothesis 1. The coaggregation of social phobia with panic disorder reflects a general tendency for phobic disorders to coaggregate with panic disorder. This hypothesis predicts that rates of social phobia, panic disorder with agoraphobia, agoraphobia without panic disorder, and simple phobia would be higher in relatives of probands with panic disorder than in relatives of normal controls.

Hypothesis 2. The co-occurrence of social phobia and panic disorder in families is not due to familial cotransmission. In this case, social phobia and panic disorder would co-occur in relatives of each proband group at rates greater than that which would be expected by chance alone, but the strength of the association between social phobia and panic disorder would not vary across the relatives of the four proband groups.

Hypothesis 3. The reported association between social phobia and panic disorder is spurious. One potential cause of a spurious association would be the misdiagnosis of agoraphobia, which is known to co-occur with panic disorder, as social phobia.

Herein, we further analyze data from our family study to test these alternative hypotheses.

\section{RISLIIS IS}

\section{DEMOGRAPHIC AND CLINICAL CHARACTERISTICS OF PROBANDS AND RELATIVES}

The demographic and clinical characteristics of the probands and relatives have been described in detail elsewhere. ${ }^{13,14}$ Table 1 presents the demographic and clinical characteristics pertinent to this set of analyses. In brief, there were no differences among proband groups in age, marital status, number of marriages, social class, education, or religion. Proband groups were initially matched for gender and age; however, gender differences emerged when best estimators' diagnoses required reclassification or elimination of some probands. Significantly more female probands were left in the two proband groups with MDD. Table 2 shows the demographic and clinical characteristics of the FDRs by proband group. The mean current age, age at onset of panic disorder, and social class differed in the relatives of the different proband groups.

\section{Table 1. Demographic and Clinical Characteristics of Probands by Group*}

\begin{tabular}{|c|c|c|c|c|c|}
\hline & \multicolumn{4}{|c|}{ Proband Group } & \multirow[b]{2}{*}{$P$} \\
\hline & $\begin{array}{l}\text { Panic Disorder } \\
\text { Without MDD } \\
(n=30)\end{array}$ & $\begin{array}{c}\text { Panic Disorder } \\
\text { With MDD } \\
(\mathrm{n}=77)\end{array}$ & $\begin{array}{c}\text { Early-0nset } \\
\text { MDD } \\
(n=41) \\
\end{array}$ & $\begin{array}{c}\text { Never } \\
\text { Mentally III } \\
(n=45)\end{array}$ & \\
\hline \multicolumn{6}{|l|}{ Gender, No. (\%) } \\
\hline M & $10(33)$ & $13(17)$ & $5(12)$ & $25(56) 7$ & \\
\hline $\mathrm{F}$ & $20(67)$ & $64(83)$ & $36(88)$ & $20(44)]$ & $<.001$ \\
\hline Mean (SD) age, $y$ & $43.3(12.5)$ & $42.6(8.8)$ & $43.9(12.5)$ & $48.0(10.5)$ & .06 \\
\hline \multicolumn{6}{|l|}{ Marital status, No. (\%) } \\
\hline Single & $5(17)$ & $7(9)$ & $7(17)$ & $6(13)$ & \\
\hline Married, remarried, or common-law marriage & $23(77)$ & $55(71)$ & $28(68)$ & $34(76)$ & \\
\hline Separated or divorced & $1(3)$ & $13(17)$ & $5(12)$ & $2(4)$ & .40 \\
\hline Widowed & $1(3)$ & $2(3)$ & $1(2)$ & $3(7)$ & \\
\hline \multicolumn{6}{|l|}{ Social class, No. $(\%) \dagger$} \\
\hline 1 and 2 & $7(24)$ & $24(31)$ & $15(36)$ & $23(51)$ & \\
\hline 3 & $12(41)$ & $29(38)$ & $14(34)$ & $10(22)$ & .28 \\
\hline 4 and 5 & $10(35)$ & $24(31)$ & $12(29)$ & $12(27)$ & \\
\hline Mean (SD) age at onset of panic disorder, y & $27.2(8.9)$ & $28.1(10.4)$ & NA & NA & .83 \\
\hline
\end{tabular}

*MDD indicates major depression; NA, not applicable

$\dagger$ Defined by the five-level Hollingshead index. 


\section{TEST OF HYPOTHESIS 1}

\section{Rates of Disorders in FDRs}

Table 3 shows the age-corrected lifetime rates of social phobia, panic disorder with and without agoraphobia, agoraphobia without panic disorder, and simple phobia in FDRs of each proband group. The lifetime rate of social phobia in the adult FDRs of probands with panic disorder without MDD is $5.9 \%$, which is significantly higher than the rates in the adult FDRs of the other three proband groups.

In Table 3, row 2, we excluded probands with comorbid social phobia from the analysis to eliminate the possibility that the higher rate of social phobia in relatives of probands with only panic disorder was due to the presence of social phobia in the probands. The lifetime rate of social phobia in the adult FDRs of probands with panic disorder remained significantly higher than in the adult FDRs of the other three proband groups.

As expected, the rates of panic disorder with and without agoraphobia are both significantly greater in the adult FDRs of the probands with panic disorder alone or panic disorder with MDD. Although the rates of agoraphobia without panic disorder and simple phobia were highest in relatives of the probands with panic disorder without MDD, the differences among the four proband groups did not reach statistical significance for these disorders.

\section{Adjusted Hazard Ratios in FDRs}

Table 4 presents the results of proportional hazards regression models, from which hazard ratios with $95 \%$ confidence intervals were derived. These analyses test whether the relatives of each ill proband group have a higher risk for social phobia, panic disorder with and without agoraphobia, agoraphobia without panic disorder, or simple phobia than the relatives of normal controls. The regression models in Table 4 control for source from which the proband was recruited and for age, gender, and interview status of the relatives.

Table 4 shows that relatives of probands with panic disorder without depression are more than five times as likely to have social phobia than relatives of the never mentally ill probands. This risk remains significantly elevated when the probands with comorbid social phobia and their relatives are excluded from the analysis. Relatives of the other two ill proband groups do not differ significantly from relatives of the never mentally ill probands with regard to risk for social phobia.

Table 4 also shows that relatives of probands with panic disorder with or without depression have an increased risk for panic disorder when compared with relatives of normal controls. When the FDRs with panic disorder are subdivided into those with or without agoraphobia, the proportional hazards remain elevated in the relatives of the two proband groups with panic disorder, although the smaller number of subjects in each group limits the statistical power of these comparisons. The risk for agoraphobia without panic disorder is also increased in relatives of probands with panic disorder without MDD when compared with relatives of normal controls. The risk for simple phobia is not significantly different in relatives of probands with panic disorder without depression from that in relatives of normal controls.

\section{TEST OF HYPOTHESIS 2}

The adjusted hazard ratios in Table 4 show that relatives of probands with panic disorder (without MDD) have

Table 2. Demographic and Clinical Characteristics of Adult First-degree Relatives by Proband Group*

\begin{tabular}{|c|c|c|c|c|c|}
\hline & \multicolumn{4}{|c|}{ Proband Group } & \multirow[b]{2}{*}{$P$} \\
\hline & $\begin{array}{l}\text { Panic Disorder } \\
\text { Without MDD }\end{array}$ & $\begin{array}{l}\text { Panic Disorder } \\
\text { With MDD }\end{array}$ & $\begin{array}{l}\text { Early-Onset } \\
\text { MDD }\end{array}$ & $\begin{array}{c}\text { Never } \\
\text { Mentally III }\end{array}$ & \\
\hline \multicolumn{6}{|l|}{ All relatives ( $N=1047$ ) } \\
\hline \multicolumn{6}{|l|}{ Gender, No. (\%) } \\
\hline M & $74(52)$ & $224(51)$ & $97(46)$ & $133(52)$ & \multirow{2}{*}{.59} \\
\hline $\mathrm{F}$ & $67(48)$ & $218(49)$ & $112(54)$ & $122(48)]$ & \\
\hline Mean (SD) age, y & $50.0(18.4)$ & $48.1(18.4)$ & $49.1(18.5)$ & $52.5(19.5)$ & .03 \\
\hline \multicolumn{6}{|l|}{ Diagnosis of panic disorder } \\
\hline Number & 20 & 33 & 5 & 3 & \multirow[b]{2}{*}{.003} \\
\hline Mean (SD) age at onset, $y$ & $23.3(9.7)$ & $27.1(9.6)$ & $22.2(7.7)$ & $39.7(16.7)$ & \\
\hline \multicolumn{6}{|l|}{ Interviewed relatives ( $n=435)$} \\
\hline \multicolumn{6}{|l|}{ Marital status, No. (\%) } \\
\hline Single & $11(15)$ & $47(26)$ & $21(24)$ & $28(30)$ & \multirow{4}{*}{.36} \\
\hline Married, remarried, or common-law marriage & $51(69)$ & $106(59)$ & $54(61)$ & $47(50)$ & \\
\hline Separated or divorced & $9(12)$ & $15(8)$ & $8(9)$ & $14(15)$ & \\
\hline Widowed & $3(4)$ & $11(6)$ & $5(6)$ & $5(5)$ & \\
\hline \multicolumn{6}{|l|}{ Social class, No. $(\%) \dagger$} \\
\hline 1 and 2 & $20(27)$ & $38(21)$ & $30(34)$ & $35(37)$ & \multirow{3}{*}{.054} \\
\hline 3 & $32(43)$ & $73(41)$ & $37(42)$ & $34(36)$ & \\
\hline 4 and 5 & $22(30)$ & $68(38)$ & $21(24)$ & $25(27)]$ & \\
\hline
\end{tabular}

* Information on age, gender, and age at onset of panic disorder is available for all relatives. Information on other demographics is available only for interviewed relatives. MDD indicates major depression; NS, not significant.

tDefined by the five-level Hollingshead index. 


\begin{tabular}{|c|c|c|c|c|c|}
\hline & \multicolumn{4}{|c|}{ Proband Group } & \multirow[b]{2}{*}{$P$} \\
\hline & $\begin{array}{l}\text { Panic Disorder } \\
\text { Without MDD }\end{array}$ & $\begin{array}{l}\text { Panic Disorder } \\
\text { With MDD }\end{array}$ & $\begin{array}{l}\text { Early-Onset } \\
\text { MDD }\end{array}$ & $\begin{array}{c}\text { Never } \\
\text { Mentally III }\end{array}$ & \\
\hline \multicolumn{6}{|l|}{ Subjects } \\
\hline No. of probands & 30 & 77 & 41 & 45 & \\
\hline No. of relatives & 141 & 442 & 209 & 255 & \\
\hline \multicolumn{6}{|l|}{ Disorder in relatives, $\%$} \\
\hline Social phobia $(n=23)$ & 5.93 & 1.62 & 2.00 & 1.59 & .02 \\
\hline Social phobia (probands with comorbid social & & & & & \\
\hline phobia and their FDRs excluded) $(n=22) \dagger$ & 6.58 & 1.93 & 2.27 & 1.59 & .04 \\
\hline Panic disorder with or without agoraphobia ( $n=61)$ & 16.14 & 9.28 & 2.61 & 1.82 & $<.001$ \\
\hline Panic disorder with agoraphobia $(n=31)$ & 8.97 & 4.12 & 2.06 & 1.40 & $<.001$ \\
\hline Panic disorder without agoraphobia $(n=30)$ & 7.70 & 5.28 & 5.49 & 4.17 & $<.001$ \\
\hline Agoraphobia without panic disorder $(n=16) \ddagger$ & 5.45 & 1.27 & 1.03 & 0.39 & .07 \\
\hline Simple phobia $(n=64)$ & 10.73 & 7.15 & 8.14 & 4.14 & .08 \\
\hline
\end{tabular}

*MDD indicates major depression; FDR, first-degree relative.

$\dagger$ Six probands with comorbid social phobia and panic disorder (without MDD) and their FDRs excluded.

$\ddagger$ Includes cases with any evidence of limited-symptom, near, spontaneous, or situational panic attacks in persons with agoraphobia who do not meet the full criteria for panic disorder.

an increased risk for both social phobia and panic disorder when compared with relatives of normal controls. From the ECA study, we know that social phobia is often comorbid with panic disorder in the community. ${ }^{\mathrm{l}} \mathrm{We}$ hypothesized that the higher rates of social phobia in relatives of probands with panic disorder without MDD might be explained by shared nonfamilial risk factors or by one disorder causing the other in individuals. Table 5 presents a test of this hypothesis.

The analyses shown in Table 5 test whether social phobia and panic disorder co-occurred with greater probability than that due to chance alone in relatives of the different proband groups. Furthermore, these analyses examine whether the strength of the association between the two disorders in relatives varied across proband groups. Table 5 presents a series of $2 \times 2$ contingency tables arrayed by proband group. Each table shows the social phobia status of relatives cross-classified by whether they had panic disorder. A measure of the extent to which comorbidity greater than that due to chance alone exists is given by the odds ratio (odds of a relative having social phobia given that he or she has panic disorder compared with the odds of the relative having social phobia given that he or she does not have panic disorder). If the value of the odds ratio is significantly greater than 1 , it can be concluded that the comorbidity is greater than that due to chance alone. Furthermore, the greater the value of the odds ratio, the stronger the association between social phobia and panic disorder in the relatives.

As Table 5 shows, the odds ratios for the relatives of the three ill proband groups are all significantly greater than 1 . The odds ratio for the relatives of the never mentally ill probands cannot be calculated because there were no relatives with comorbid panic disorder and social phobia. At the bottom of Table 5, the Breslow-Day test for the homogeneity of the odds ratios shows no significant differences in the odds ratios in the relatives across the different proband cells. These results suggest that, al- though there is a strong association between social phobia and panic disorder, as reflected by the common odds ratio of 9.99 (ie, almost a tenfold increased risk for social phobia if the relative also has panic disorder), the strength of this association does not differ significantly by proband group.

\section{TEST OF HYPOTHESIS 3}

To test whether diagnostic misclassification of agoraphobia as social phobia contributed to finding higher rates of social phobia in relatives of probands with panic disorder, we reviewed all of the available diagnostic information on the 23 relatives in whom social phobia was diagnosed. Twenty-two of the 23 relatives with social phobia had been directly interviewed. Eleven of the 23 relatives with social phobia met the criteria for panic disor$\operatorname{der}(n=9)$ or experienced subsyndromal panic attacks $(\mathbf{n}=2)$. In eight relatives, both agoraphobia and social phobia were diagnosed. Eleven relatives with social phobia did not have comorbid diagnoses of either panic disorder or agoraphobia.

We compared the demographic and clinical characteristics of the FDRs with social phobia, panic disorder, or agoraphobia. Several differences increased our confidence in the diagnostic distinctions: (1) the mean age at onset of social phobia was earlier than the mean ages at onset of panic disorder or agoraphobia; (2) the femalemale ratio for social phobia was closer to unity than the gender ratios for panic disorder or agoraphobia; and (3) the percentage of relatives with social phobia who had never married was higher than that of the relatives with panic disorder or agoraphobia. These demographic and clinical differences between the subjects with social phobia, panic disorder, or agoraphobia suggest that the cases of social phobia were clinically distinct from agoraphobia.

Early drafts of the DSM-IV proposed discrete and generalized subtypes of social phobia, ${ }^{35}$ and the DSM-IV in- 
Table 4. Adjusted Hazard Ratios With $95 \%$ Cls Comparing Rates of DSM-III-R Phobias and Panic Disorder in Relatives of III and Relatives of Normal Control Probands ( $N=1047)$ by Proband Group*

\begin{tabular}{|c|c|c|c|}
\hline \multirow[b]{2}{*}{ Disorder in Relatives } & \multicolumn{3}{|c|}{ Proband Group, Hazard Ratioł $(95 \% \mathrm{Cl})$} \\
\hline & $\begin{array}{l}\text { Panic Disorder } \\
\text { Without MDD }\end{array}$ & $\begin{array}{l}\text { Panic Disorder } \\
\text { With MDD }\end{array}$ & Early-0nset MDD \\
\hline Social phobia $(n=23)$ & $5.44(1.38-21.54) \|$ & $1.52(0.37-6.27)$ & $0.98(0.21-4.52)$ \\
\hline $\begin{array}{l}\text { Social phobia (probands with comorbid social phobia } \\
\text { and their FDRs excluded) }(n=22) \ddagger\end{array}$ & $6.70(1.64-27.35)$ I & $2.04(0.49-8.51)$ & $1.20(0.27-5.37)$ \\
\hline Panic disorder with or without agoraphobia $(\mathrm{n}=61)$ & $8.77(2.28-33.78)$ & $5.66(1.51-21.16) \|$ & $2.14(0.49-9.34)$ \\
\hline Panic disorder with agoraphobia $(n=31)$ & $8.28(1.53-44.72) \|$ & $4.25(0.80-22.42) \#$ & $2.88(0.51-16.35)$ \\
\hline Panic disorder without agoraphobia $(n=30)$ & $9.48(0.97-92.43) \#$ & $7.51(0.81-69.97) \#$ & $1.06(0.06-18.47)$ \\
\hline Agoraphobia without panic disorder $(n=16) \S$ & $13.73(1.38-136.97) \|$ & $5.39(0.55-53.29)$ & $3.01(0.26-35.30)$ \\
\hline Simple phobia $(n=64)$ & $1.95(0.70-5.40) \#$ & $1.57(0.62-3.97)$ & $1.06(0.42-2.70)$ \\
\hline
\end{tabular}

* Cl indicates confidence interval; $M D D$, major depression; and FDR, first-degree relatives.

†Adjusted for source from which proband was recruited and gender, age, and interview status of relative.

$\ddagger$ Six probands with comorbid social phobia and panic disorder (without MDD) and their FDRs were excluded.

§Includes cases with any evidence of limited-symptom, near, spontaneous, and situational panic attacks in persons with agoraphobia who do not meet the

full criteria for panic disorder. Because of the small number of cases, only gender and interview status of the relative could be controlled for.

$\| \mathrm{P}<.05$.

$\prod \mathbb{P}<.01$.

$\# .05<\mathrm{P}<10$.

cludes a specification for a generalized type. ${ }^{36}$ The discrete subtype involves one or two specific fears, whereas the generalized subtype includes most social situations and may be more difficult to distinguish from agoraphobia. Data from the ECA study support the validity of the discrete and generalized subtypes of social phobia. ${ }^{37}$ In our sample of relatives, 17 of the 23 cases of social phobia were of the discrete subtype, which involved fear and avoidance of public speaking, eating in public, the use of public lavatories, performing, speaking on the telephone, or asking directions. This preponderance of cases with discrete social phobias further supports the validity of our diagnostic distinction between social phobia and agoraphobia.

\section{COMMENT}

In this study, we tested several alternative hypotheses in an attempt to explain our previously reported finding of familial coaggregation of social phobia and panic disorder.

\section{HYPOTHESIS 1}

We found that there is a fivefold increased risk for social phobia in relatives of probands with panic disorder without MDD compared with relatives of never mentally ill probands. The increased risk for social phobia in relatives of probands with panic disorder is not accounted for by the occurrence of comorbid social phobia in probands. As previously reported, relatives of probands with panic disorder had a higher risk for panic disorder than relatives of the never mentally ill probands. Relatives of probands with panic disorder had an increased risk for agoraphobia without panic disorder when compared with relatives of the never mentally ill probands. There was no significant difference in the risk for simple phobia when comparing relatives of probands who have panic disorder with relatives of con- trols. These results suggest that social phobia and agoraphobia aggregate in relatives of probands with panic disorder without MDD but that simple phobia does not.

\section{HYPOTHESIS 2}

We found that social phobia and panic disorder cooccurred in relatives of all three ill proband groups at a higher-than-chance level. Relatives with panic disorder had an almost tenfold increased risk for social phobia compared with relatives without panic disorder. However, the strength of the association between social phobia and panic disorder in relatives did not vary across different proband cells.

The uniformly strong association between social phobia and panic disorder in relatives regardless of proband group suggests that nonfamilial factors may account for the high comorbidity of these two disorders. Therefore, the increased rate of social phobia in relatives of probands with only panic disorder compared with relatives of normal controls may be accounted for by the high rates of panic disorder in the relatives of probands with only panic disorder combined with a tendency for these two disorders to co-occur. In other words, panic disorder in the relatives may be a risk factor for social phobia.

\section{HYPOTHESIS 3}

We found that cases of social phobia in relatives were clearly differentiable from agoraphobia based on clinical factors such as the fear and avoidance of specific social situations as opposed to the more general avoidance behaviors usually seen in agoraphobia. Furthermore, the gender ratio, mean ages at onset, and marital status of the relatives with social phobia are consistent with the demographic characteristics that have been reported by other investigators and are distinct from those of the relatives with panic disorder or agoraphobia.

Our finding that relatives of probands with panic dis- 
Table 5. Association Between Panic Disorder and Social Phobia in Relatives by Proband Group*

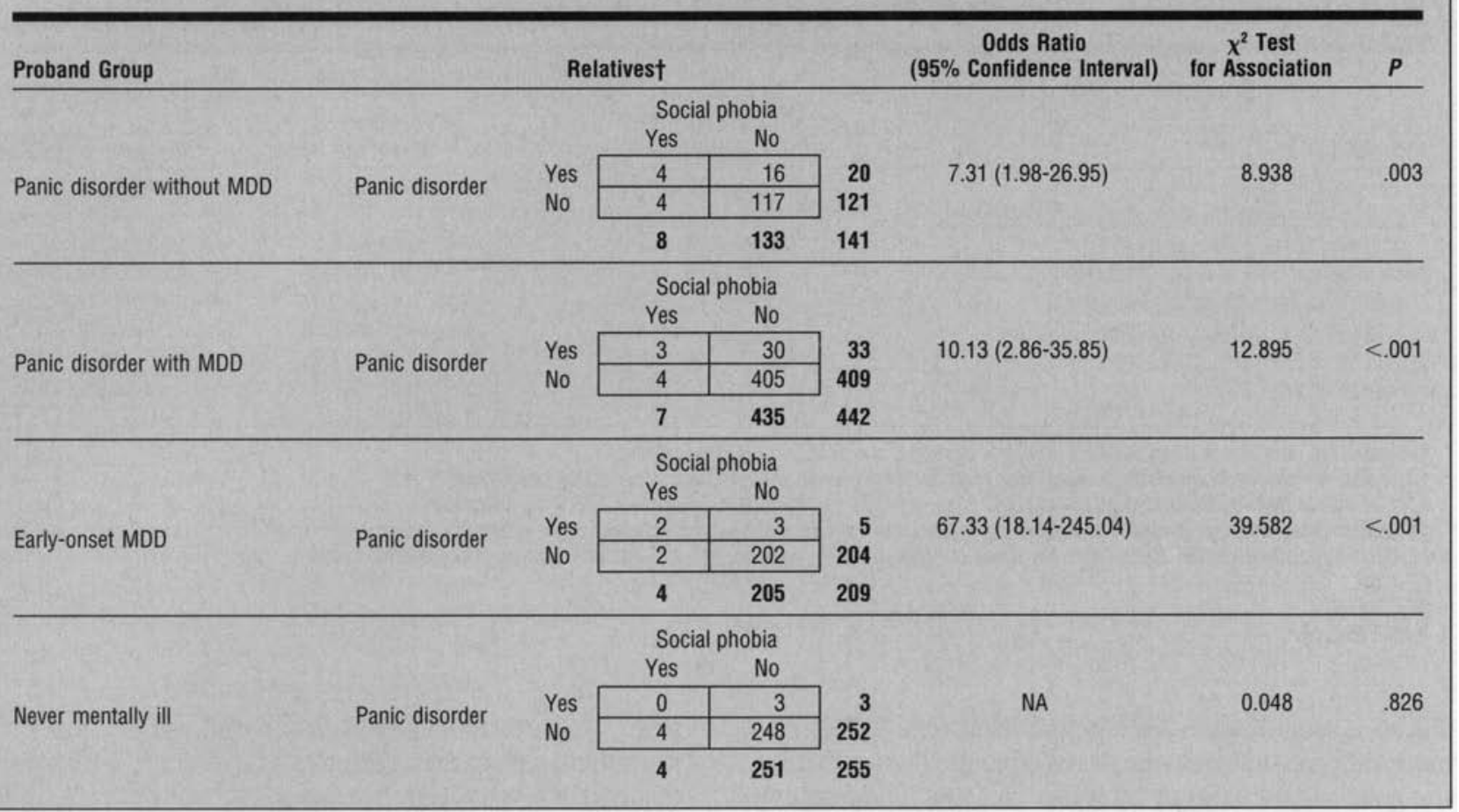

*Breslow-Day test for homogeneity of the odds ratio: $\chi^{2}=3.940, \mathrm{df}=3, \mathrm{P}=.268$. Estimate of the common odds ratio: odds ratio (95\% confidence interval): 9.99 (4.59, 21.73), $P<.001$. MDD indicates major depression; NA, not applicable.

†Values are numbers of relatives. Boldfaced numbers outside the box are totals.

order have an increased risk for social phobia is consistent with previously published studies in children by Weissman et $\mathrm{al}^{10}$ and in adults by Coryell et $\mathrm{al}^{11}$ and Leckman et al. ${ }^{15}$ These studies found increased risks for RDC phobias in relatives of probands with panic disorder. However, these studies did not differentiate social phobia from other phobic disorders and, therefore, are not directly comparable. Furthermore, all of the probands in these studies had comorbid MDD. We did not find elevated rates of social phobia in the relatives of probands with comorbid panic disorder and MDD.

In contrast to our finding of an increased rate of social phobia in relatives of probands with panic disorder without MDD, Mendlewicz et $a^{25}$ did not find increased rates of social or simple phobias in relatives of probands with panic disorder. However, their report did not distinguish social from simple phobias so that distinct risks for social phobia could not be determined from their study. This is important because of our finding that the risk for simple phobia was not significantly higher in relatives of probands with panic disorder when compared with relatives of the never mentally ill probands.

Other studies that used DSM-III or DSM-III-R criteria did not find an increased risk for social phobia in relatives of probands with panic disorder. ${ }^{7,16.21}$ This conflicts with our finding that social phobia aggregated in the relatives of probands with panic disorder without comorbid MDD, but the discrepancy may be explained by methodological differences. Bellodi and colleagues ${ }^{7}$ and Reich and Yates ${ }^{21}$ did not find a familial aggregation of social phobia with panic disorder, but their results were based on the family history method. Relatives were not directly interviewed as was done in our study, probably resulting in underestimation of the prevalence of social phobia and other disorders compared with our direct interview study. ${ }^{38,39}$

Noyes et al $^{16}$ determined diagnoses of anxiety disorders according to the hierarchy outlined in the DSMIII, with a single primary anxiety diagnosis assigned according to the predominant anxiety symptoms. De Ruiter and colleagues ${ }^{4}$ found that in patients with comorbid panic disorder, agoraphobia, and social phobia, social phobia more frequently was considered the primary illness when primacy was determined temporally than when primacy was assigned according to the greatest interference with functioning. Noyes and colleagues may have underestimated the rates of social phobia in the relatives of probands with panic disorder by defining social phobia as the secondary anxiety diagnosis. Social phobia is frequently assigned as an additional diagnosis in patients in whom another anxiety disorder is judged as principal. $^{40}$

Fyer and associate ${ }^{20}$ found an increased risk for social phobia in relatives of probands with social phobia. Recognizing the evidence for the familiality of social phobia, we controlled for comorbid social phobia in the probands in our study, but this did not account for our finding of an increased risk for social phobia in relatives of probands with panic disorder.

\section{LIMITATIONS}

In this study, we tested three alternative hypotheses regarding the familial coaggregation of social phobia 
and panic disorder. A fourth hypothesis suggests that social phobia comorbid with panic disorder is a distinct syndrome that aggregates in families independently of either disorder alone. We could not fully test this hypothesis for lack of a social phobia proband group.

However, we were able to partially test this hypothesis by comparing rates of panic disorder without social phobia, panic disorder with social phobia, and social phobia without panic disorder in relatives of probands with panic disorder with and without social phobia. The rates of these three syndromes were not significantly different when comparing relatives of probands with panic disorder with and without social phobia.

This limited test suggests that social phobia comorbid with panic disorder is not a single, distinct syndrome with independent familial aggregation. A study with a social phobia proband group without panic disorder would be necessary to test this hypothesis fully. This study was not designed originally with a social phobia proband group because the finding of coaggregation of social phobia with panic disorder was unexpected.

Several authors ${ }^{8,12}$ have commented on the difficulties in differentiating between social phobia and panic disorder with agoraphobia. Although we had concerns that misdiagnosis might have contributed to our finding, we found that differences in ages at onset, gender ratio, marital status, and discreteness of social fears supported the diagnostic distinctions we made between social phobia and agoraphobia.

It is not clear why social phobia did not aggregate in the relatives of probands with panic disorder and MDD. One possible explanation is heterogeneity in the proband group with panic disorder and MDD, which may have included subtypes of panic disorder with differing associations with social phobia.

Rosenbaum and colleagues ${ }^{41}$ have suggested that behavioral inhibition in children may be a precursor to the development of panic disorder and social phobia in adults. Several family studies have shown an association between panic disorder and social phobia in parents and behavioral inhibition in children. ${ }^{42,43}$ Behavioral inhibition in children of parents with social phobia or panic disorder may be a marker for the familial transmission of a shared diathesis for these disorders.

Although familial transmission of a shared diathesis for panic disorder and social phobia is a possible explanation for the findings of our study, we could not test this hypothesis because of the lack of a social phobia proband group without panic disorder. However, Fyer and colleagues ${ }^{20}$ did not find an increased risk for panic disorder in the relatives of patients with social phobia, which would be expected if the two disorders are alternate expressions of an underlying trait that is transmitted familially.

Comorbidity may be due to common nonfamilial risk factors or one disorder causing the other. Early nonfamilial environmental stressors may predispose individuals to both social phobia and panic disorder. Social phobia may be a risk factor for development of panic disorder or vice versa. Our study could not differentiate among these possible explanations for comorbidity. Longitudinal follow-up studies would be required to explore these possibilities more fully.

Given the small number of cases of social phobia on which we report, these results should be regarded cautiously and require replication. Family studies with the full range of mutually exclusive proband groups (panic disorder with no social phobia, panic disorder with social phobia, social phobia without panic disorder, and normal controls) are needed to clarify the relationship between social phobia and panic disorder.

\section{Accepted for publication April 11, 1995.}

This work was supported by grants $\mathrm{MH}-438781, \mathrm{MH}-$ 28274 , and MH-30906 from the National Institute of Mental Health, Bethesda, Md, and National Institute of Mental Health Research Training grant 5T32MH16434 (Dr Wolk), administered through Columbia University, New York, NY.

Reprint requests to New York State Psychiatric Institute, Unit 14, $722 \mathrm{~W}$ 168th St, New York, NY 10032 (Dr Horwath).

\section{REFERINCES}

1. Schneier FR, Johnson J, Hornig CD, Liebowitz MR, Weissman MM. Social phobia: comorbidity and morbidity in an epidemiologic sample. Arch Gen Psychiatry. 1992;49:282-288.

2. Van Ameringen M, Mancini C, Styan G, Donison D. Relationship of social phobia with other psychiatric illness. J Affect Disord. 1991;21:93-99.

3. Barlow DH, DiNardo PA, Vermilyea BB, Vermilyea J, Blanchard EB. Comorbidity and depression among the anxiety disorders. J Nerv Ment Dis. 1986; 174:63-72.

4. de Ruiter C, Rijken H, Garssen B, van Schaik A, Kraaimaat F. Comorbidity among the anxiety disorders. $J$ Anxiety Disord. 1989;3:57-68.

5. Stein MB, Shea CA, Unde TW. Social phobic symptoms in patients with panic disorder: practical and theoretical implications. Am J Psychiatry. 1989;146. 235-238.

6. Reiter SR, Otto MW, Pollack MH, Rosenbaum JF. Major depression in panic disorder patients with comorbid social phobia. J Affect Disord. 1991;22:171177.

7. Bellodi L, Battaglia M, Diaferia G, Draisci A, Sciuto G. Lifetime prevalence of depression and family history of patients with panic disorder and social phobia. Eur Psychiatry. 1993;8:147-152.

8. Unde TW, Tancer ME, Black B, Brown TM. Phenomenology and neurobiology of social phobia: comparison with panic disorder. J Clin Psychiatry. 1991;52 (suppl):31-40.

9. Fyer AJ, Mannuzza S, Gallops MS, Martin LY, Aaronson C, Gorman JM, Leibowitz MR, Klein DF. Familial transmission of simple phobias and fears: a preliminary report. Arch Gen Psychiatry. 1990;47:252-256.

10. Weissman MM, Leckman JF, Merikangas KR, Gammon GD, Prusoff BA. Depression and anxiety disorders in parents and children: results from the Yale family study. Arch Gen Psychiatry. 1984;41:845-852.

11. Coryell WH, Endicott J, Andreassen NC, Keller MB, Clayton PJ, Hirschfeld RMA, Scheftner WA, Winokur G. Depression and panic attacks: the significance of overlap as reflected in follow-up and family study data. Am J Psychiatry. 1988; 145:293-300.

12. Mannuzza S, Fyer AJ, Liebowitz MR, Klein DF. Delineating the boundaries of social phobia: its relationship to panic disorder and agoraphobia. J Anxiety Disord. 1990;4:41-59.

13. Weissman $M M$, Wickramaratne $P$, Adams $P$, Lish J, Horwath $E$, Charney $D$, Woods SW, Leeman E, Frosch E. The relationship between panic disorder and major depression: a new family study. Arch Gen Psychiatry. 1993;50:767-780.

14. Goldstein RB, Weissman MM, Adams PB, Horwath E, Lish JD, Charney D, Woods SW, Sobin C, Wickramaratne PJ. Psychiatric disorders in relatives of probands with panic disorder and/or major depression. Arch Gen Psychiatry. 1994;51:383-394.

15. Leckman JF, Weissman MM, Merikangas KR, Pauls DL, Prusoff BA. Panic dis- 
order and major depression: increased risk of depression, alcoholism, panic and phobic disorders in families of depressed probands with panic disorder. Arch Gen Psychiatry. 1983;40:1055-1060.

16. Noyes $R$, Crowe RR, Harris EL, Hamra BJ, McChesney CM, Chaudhry DR. Relationship between panic disorder and agoraphobia: a family study. Arch Gen Psychiatry. 1986;43:227-232.

17. Crowe RR, Noyes R, Pauls DL, Slymen D. A family study of panic disorder. Arch Gen Psychiatry. 1983;40:1065-1069.

18. Hopper JL, Judd FK, Derrick PL, Burrows GD. A family study of panic disorder. Genet Epidemiol. 1987;4:33-41.

19. Moran C, Andrews G. The familial occurrence of agoraphobia. Br J Psychiatry. 1985;146:262-267.

20. Fyer AJ, Mannuzza S, Chapman TF, Liebowitz MR, Klein DF. A direct interview family study of social phobia. Arch Gen Psychiatry. 1993;50:286-293.

21. Reich J, Yates W. Family history of psychiatric disorders in social phobia. Compr Psychiatry. 1988;29:72-75.

22. Spitzer RL, Endicott J, Robins E. Research Diagnostic Criteria for a Selected Group of Functional Disorders. 3rd ed. New York, NY: Biometrics Research Division, New York State Psychiatric Institute; 1977.

23. American Psychiatric Association. Diagnostic and Statistical Manual of Mental Disorders, Third Edition. Washington, DC: American Psychiatric Association; 1980.

24. American Psychiatric Association. Diagnostic and Statistical Manual of Mental Disorders, Revised Third Edition. Washington, DC: American Psychiatric Association; 1987.

25. Mendlewicz J, Papadimitriou G, Wilmotte J. Family study of panic disorder: comparison with generalized anxiety disorders, major depression, and normal subjects. Psychiatr Genet. In press.

26. Mannuzza S, Fyer AJ, Klein DF, Endicott J. Schedule for affective disorders and schizophrenia-lifetime version (modified for the study of anxiety disorders): rationale and conceptual development. J PSychiatr Res. 1986;20:317-325.

27. Weissman MM, Wickramaratne $P$, Merikangas KR, Prusoff BA, Caruso KA, Kidd KK, Gammon GD. Onset of major depression in early adulthood: increased familial loading and specificity. Arch Gen Psychiatry. 1984;41:1136-1143.

28. Robins LN, Heizer JE, Croughan J, Ratcliff KS. National Institute of Mental Health Diagnostic Interview Schedule: its history, characteristics, and validity. Arch Gen Psychiatry. 1981;38:381-389.

29. Thompson DG, Kidd JR, Weissman MM. A procedure for the efficient collection and processing of pedigree data suitable for genetic analysis. $J$ Psychiatr Res. 1980;15:291-303.

30. Andreasen NC, Endicott J, Spitzer RL, Winokur G. The family history method using diagnostic criteria: reliability and validity. Arch Gen Psychiatry. 1977;
34:1229-1235.

31. Weissman MM, Gershon ES, Kidd KK, Prusoff BA, Leckman JF, Dibble E, Hamovit J, Thompson WD, Pauls DL, Guroff JJ. Psychiatric disorders in the relatives of probands with affective disorders. Arch Gen Psychiatry. 1984;41:1321.

32. Mannuzza S, Fyer AJ, Endicott J, Klein DF. Family Informant Schedule and Criteria (FISC). New York, NY: Anxiety Disorders Clinic, New York State Psychiatric Institute; 1985.

33 Leckman JF, Sholomskas D, Thompson WD, Belanger A, Weissman MM. Best estimates of lifetime psychiatric diagnosis: a methodological study. Arch Gen Psychiatry. 1982;39:879-883.

34. Wickramaratne PJ, Weissman MM, Horwath E, Adams P. The familial aggregation of panic disorder by source of proband ascertainment. Psychiatr Genet. 1994:4:125-133.

35. American Psychiatric Association Task Force on DSM-IV. DSM-IV Options Book: Work in Progress. Washington, DC: American Psychiatric Association; 1991.

36. American Psychiatric Association. Diagnostic and Statistical Manual of Mental Disorders, Fourth Edition. Washington, DC: American Psychiatric Association; 1994.

37. Horwath E, Johnson J, Hornig CD, Weissman MM. Social phobia diagnostic subtypes and the relationship between social phobia and panic disorder/ agoraphobia. In: Frances A, Pincus $H$, Widiger TA, eds. DSM-IV Sourcebook. Washington, DC: American Psychiatric Press Inc. In press.

38. Mendlewicz J, Fleiss $\mathrm{JL}$, Cataldo M, Rainer JD. Accuracy of the family history method in affective illness. Arch Gen Psychiatry. 1975;32:309-314.

39. Lavori PW, Keller MB, Endicott J. Improving the validity of FH-RDC diagnosis of major affective disorder in uninterviewed relatives in family studies: a modelbased approach. J Psychiatr Res. 1988;22:249-259.

40. DiNardo PA, Moras K, Barlow DH, Rapee RM, Brown TA. Reliability of DSMIII-R anxiety disorder categories: using the Anxiety Disorders Interview ScheduleRevised (ADIS-R). Arch Gen Psychiatry. 1993;50:251-256.

41. Rosenbaum JF, Biederman J, Hirshfeld DR, Bolduc EA, Chaloff J. Behavioral inhibition in children: a possible precursor to panic disorder or social phobia. $J$ Clin Psychiatry. 1991;52(suppl):5-9.

42. Rosenbaum JF, Biederman J, Gersten M, Hirshteld DR, Meminger SR, Herman JB, Kagan J, Reznick JS, Snidman S. Behavioral inhibition in children of parents with panic disorder and agoraphobia. Arch Gen Psychiatry. 1988;45: $463-470$.

43. Rosenbaum JF, Biederman J, Hirshfeld DR, Bolduc EA, Faraone SV, Kagan J, Snidman N, Reznick JS. Further evidence of an association between behavioral inhibition and anxiety disorders: results from a family study of children from a non-clinical sample. J Psychiatr Res. 1991;25:49-65.

The ARCHIVES is available by request to nonfederal physicians in the United States ( 50 states and Washington, DC) whose official American Medical Association masterfile record shows a primary specialty of psychiatry or child psychiatry in an office- or hospital-based practice as a staff physician, resident in training beyond the first year, or clinical fellow.

If you meet the above qualification criteria and are not currently receiving the ARCHIVES and would like to receive it each month, you must complete a free subscription request card. To receive a request card, please write to Kathryn Osten, American Medical Association, Circulation Processing Department, 515 N State St, Chicago, IL 60610 (fax 312-464-2580). A subscription request card will be sent to you in response. If you are a resident or fellow, please include verification of your training program and a complete mailing address. 